\section{EDITORIAL BOARD}

Editor and Chair

Mary Beth Weber, Rutgers University

\section{Members}

Julian Everett Allgood, New York University

David Banush, Brown University

Sian Doria Brannon, University of North Texas

Elise Calvi, Indiana Historical Society

Steven B. Carrico, University of Florida

Christopher J. Cronin, University of Chicago

Nadine Ellero, Auburn University

Andrew S. Hart, University of North Carolina at Chapel Hill

Steven A. Knowlton, University of Memphis

Birdie MacLennan, University of Vermont

Philip E. Schreur, Stanford

University

Michele Seikel, Oklahoma State

University, Stillwater

Anne M. Sleeman, Community

College of Baltimore County

Catonsville

Lori Terrill, University of Wyoming

Elaine L. Westbrooks, University of Michigan

Lynn N. Wiley, University of Illinois at Urbana-Champaign

Oksana Zavalina, University of North Texas

\section{Ex-Officio Members}

Norm Medeiros, Haverford College Book Review Editor, LRTS

Alice Platt, YBP

Editor, ALCTS Newsletter Online

Charles Wilt, Executive Director, ALCTS

\title{
Editorial: Advocacy for Technical Services
}

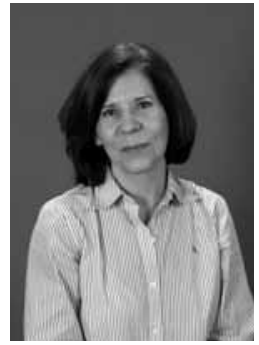

Mary Beth Weber

7 he term "advocacy," when used in reference to libraries, does not immediately bring to mind technical services. In 2011, I was invited to chair the ALCTS Advocacy Task Force. ${ }^{1}$ The task force was created in response to comments made by respondents to the "Reshaping" membership survey, ${ }^{2}$ suggesting that advocacy is an area that ALCTS should examine. My colleagues Erin Boyd, Eleanor Cook, Louise Ratliff, and Duncan Stewart also served on the task force. During the course of the task force's work (which included many conference calls, countless email exchanges, and reports from various meetings), I came to realize that there is indeed a need for advocacy for technical services. It can be subtle and on a small scale, and within one's library, institution, or consortium. Or it can be on a larger scale, such as within a professional organization or the profession at large.

The task force hosted a successful e-forum titled "Advocacy: What Does it Mean for Technical Services?” in 2012. " A total of 208 messages from fifty-four participants were exchanged during the e-forum, which covered a variety of topics, including how participants defined advocacy and what it meant to them; elevator speeches for technical services; what ALCTS can do for individuals and our profession in terms of advocacy; and critical areas of need that ALCTS can serve through publications and documentation to enable members to meet the needs of their libraries and to facilitate collaborative problem solving.

As I prepared the task force's report, I researched existing advocacy resources within the American Library Association (ALA) and its divisions. ALA provides a wealth of resources, particularly the Office for Library Advocacy (OLA) (www .ala.org/offices/ola) and the Advocacy Clearinghouse (www.ala.org/advocacy/ advleg/advocacyuniversity/advclearinghouse). Notably, one of the key action areas of the ALA 2015 Strategic Plan is "Advocacy for Libraries and the Profession: The association actively works to increase public awareness of the crucial value of libraries and librarians, to promote state and national legislation beneficial to libraries and library users, and to supply the resources, training and support networks needed by local advocates seeking to increase support for libraries of all types." ALA divisions that provide advocacy resources for members include the American Association of School Librarians, the Association of College and Research Libraries, the Association of Library Trustees, Advocates, Friends and Foundations, the Association for Library Service to Children, the Library Information and Technology Association, the Public Library Association, and the Young Adult Library Services Association. It seems that technical services librarians often do not think of advocating for their work. The task force proposed the idea of "backroom advocacy," which takes place at one's job, institution and community, and involves advocating for the work of technical services, not for a particular type of library or aspect of technical services. Certain aspects of technical services (collection development and management, for example) have a public component and have greater interaction with other parts of the 
library and user community. Catalogers sometimes interact with the public when there is a major culture change, such as $R D A$ implementation. While all of the technical services areas represented by ALCTS affect our institutions' ability to provide services to our respective user communities, technical services librarians may lack mechanisms to advocate for their contributions. This in turn diminishes our ability to attract new librarians to the work we do and to ALCTS, and ultimately may be detrimental to technical services as a career path.

I attended the ALCTS Board of Directors meeting during the 2012 ALA Annual Conference to discuss the task force's report. Two groups have been formed as the result of recommendations set forth in our report:

- The ALCTS Technical Services Advocacy Resources Task Force, chaired by Louise Ratliff. This group is charged with assembling "a collection of resources, available through our website, to help ALCTS members demonstrate and articulate the value of functions in ALCTS' areas of coverage, historically known as technical services."

- The ALCTS Advocacy Coordinating Group, a new division-level committee, which will be chaired by
Olivia M. A. Madison. Eleanor Cook and Duncan Stewart will serve as ex officio members. The goal is for the committee to "enable ALCTS to play an effective role in policy development, and bring our members' expertise to many pertinent policy discussions, for the benefit of library service."

I am very excited about both of these groups, and it has been rewarding to see the positive affects of the Advocacy Task Force's recommendations. My experience has transformed my views on advocacy and has convinced me that there is indeed a strong need for technical services advocacy.

LRTS advocates for technical services by providing scholarly papers on current topics that are relevant to the needs and concerns of our profession. It provides a vehicle for technical services librarians to share information that will benefit their colleagues and provides resources such as book reviews as a professional courtesy to others. I have shared LRTS articles with nontechnical services librarians and administrators at my institution to provide timely and relevant professional information to them.

In closing, I would like to draw your attention to the papers in this issue of LRTS:

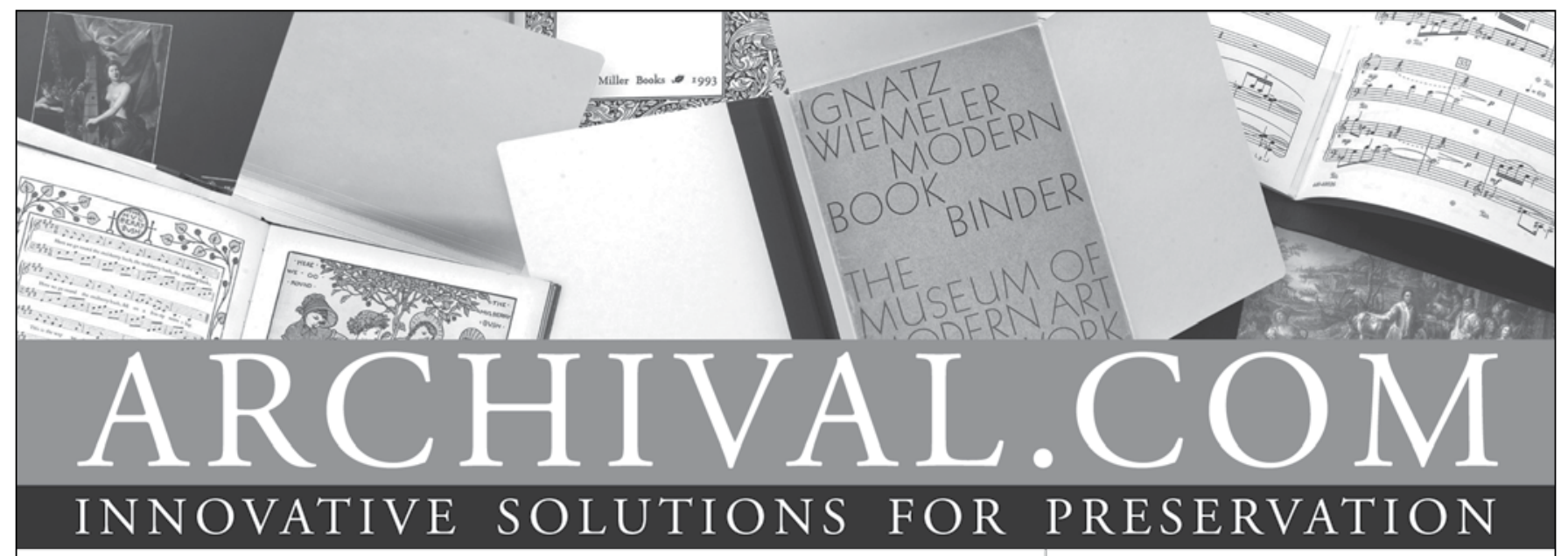

Call for a complete catalog

Pamphlet Binders

Music Binders

Archival Folders

Manuscript Folders

Hinge Board Covers

Academy Folders

Newspaper/Map Folders

Bound Four Flap

Enclosures

Archival Binders
Polypropylene Sheet

\& Photo Protectors

Archival Boards

Adhesives

Bookkeeper

Century Boxes

Conservation Cloths

Non-Glare Polypropylene

Book Covers

CoLibri Book Cover System

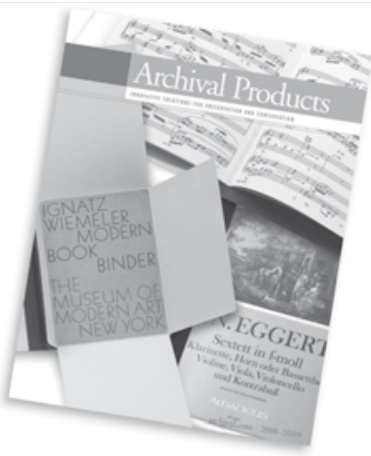

\section{ARCHIVAL PRODUCTS}

P.O. Box 1413

Des Moines, Iowa 50306-1413

Phone: 800.526 .5640

Fax: 888.220.2397

E-mail: custserv@archival.com

Web: archival.com 
- Sarah Sutton provides a review of the serials literature, 2010-11.

- Paul Moeller provides a review of the acquisitions literature, 2010-11.

- John Baga, Lona Hoover, and Robert E. Wolverton Jr. have written an annotated webliography of online, practical, and free cataloging resources. This is a new type of publication for LRTS that will greatly benefit catalogers.

- Jennifer Bazeley and Becky Yoose have written a Notes on Operations paper on using a LibGuide to communicate between technical services and public services at Miami (Ohio) University Libraries, which is an example of technical services advocacy.

\section{References}

1. Association for Library Collections and Technical Services, "Annual Report 2011-12," accessed December 20, 2012, www.ala.org/aboutala/sites/ala.org.aboutala/files/content/ governance/council/council_documents/2012an_council_ docus/cd_28_3_alcts.pdf.

2. Association for Library Collections and Technical Services, "Task Force on Re-Shaping ALCTS' Future," accessed December 20, 2012, www.ala.org/alcts/sites/ala.org.alcts/files/ content/ianda/alctsorg/reshape_rpt.pdf.

3. The archives of the e-forum are available at http://ists.ala.org/ sympa/arc/alcts-eforum/2012-02/msg00002.html. The archive is availableonlytosubscribers; directionson howtosubscribeare available at www.ala.org/alcts/confevents/upcoming/e-forum/ sympa.

4. American Library Association, "2015 Strategic Plan," accessed December 20, 2012, www.ala.org/aboutala/missionhistory/ plan.

5. Carolynne Myall, "ALCTS Technical Services Advocacy Resources TF formed," email to ALCTS Leaders discussion list, October 17, 2012.

6. Carolynne Myall, "ALCTS Advocacy Coordinating Group," email to ALCTS Leaders discussion list, December 10, 2012. 